the male nervous system functions in the stable manner of adulthood beginning very early in life, whereas, for regulation of gonadotrophin secretion, "all hypothalami are of the female type during a significant part of the life span and ... action of androgen ... in the neonatal period does not take effect until some time after puberty"s.

This work was supported by the Committee on Research, University of California. I thank F. A. Beach for reading the manuscript and the Schering Corporation for the supplies of hormones.

Department of Psychology,

University of California, Berkeley.

Received June 12; revised August 15, 1967.

${ }^{1}$ Grady, K. L., Phoenix, C. H., and Young, W. C., J. Comp. Physiol. Psychol. 59,176 (1965).

${ }^{2}$ Feder, H. H., and Whalen, R. E., Science, 147, 306 (1965).

${ }^{3}$ Feder, H. H., Phoenix, C. H., and Young, W. C., J. Endocrinol., 34, 131 (1966).

${ }^{4}$ Levine, S., and Mullins, R. F., Science, 152, 1585 (1966).

${ }^{5}$ Campbell, H. J., Nature, 210,1060 (1966).

- Swanson, H. E., and van der Werff ten Bosch, J. J., Acta Endocrinol., 47, 37 (1964).

${ }^{7}$ Zucker, I, and Feder, H. H., J. Endocrinol., 35, 423 (1966).

${ }^{8}$ Zucker, I., J. Comp. Physiol. Prychol., 63, 313 (1967).

'Wilson, J. G., and Young, W. C., Endocrinology, 29, 779 (1941).

\section{Voltage Clamp Studies on Snail (Helix aspersa) Neurones}

INVESTIGATIONS of snail neurones have shown that some cells can maintain their action potentials in solutions free of sodium ${ }^{1-4}$ and are not affected by tetrodotoxin ${ }^{3}$. These nerves may have a calcium carrying current system similar to that described in barnacle muscle ${ }^{5}$.

We have used a system where the whole membrane of the snail neurone perikaryon can be clamped at a specified voltage without showing any notching or oscillations in current $^{6}$, and the preparation showed a current waveform similar to that described by Hodgkin and Huxley ${ }^{7}$ for the squid axon.

In Fig. 1, curve $A$ shows the maximum inward current plotted against membrane potential and curve $a$ shows the steady-state outward current, when the cell is in

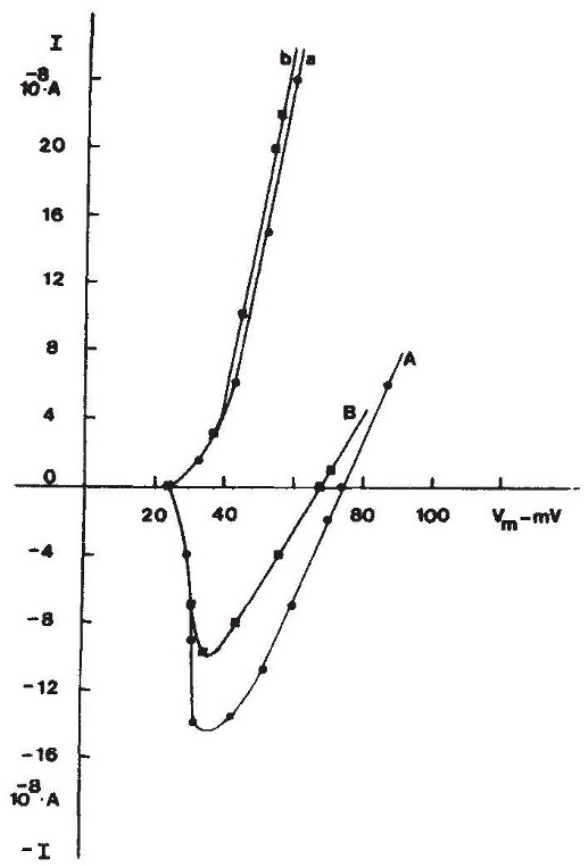
Fig. 1. Current-voltage relations of the membrane of a neurone of
Helix aspersa. A, Maximum inward current in normal Ringer; $B$, maximum inward current in sodium-free Ringer; $a$, steady-state current in normal Ringer; $b$, steady $/$ state current in sodium-free Ringer. normal Ringer (sodium, 80 mmolar; calcium, 7 mmolar). When the external solution was replaced by a sodium-free Ringer there was still an inward current (curve $B$ ) although this was less than that seen in normal Ringer. The inward current was found even in neurones washed in sodium-free solution for $20 \mathrm{~min}$. When the solution was replaced by normal Ringer, the full inward current was restored after about 100 sec.

The reduced inward current seen in sodium-free solution disappeared if the cell was placed in a solution containing neither sodium nor ealcium. Although the reduced inward current seen in sodium-free solution could be in. creased by replacement of sodium, the reduced current could not be restored by an increase of calcium up to seven times the normal value. Cells injected with EDTA showed a normal inward current in standard Ringer but not in sodium-free Ringer containing calcium.

The inward current of cells in normal Ringer was not reduced by tetrodotoxin in concentrations between $10^{-9}$ and $10^{-5} \mathrm{~g} / \mathrm{ml}$. The inward current in sodium-free solution could be abolished by charging the membrane at $30 \mathrm{mV}$ or higher and maintaining this potential for more than $20 \mathrm{~min}$. The current was re-established when the cells were replaced in normal Ringer.

There may be a small store of sodium ions closely associated with the nerve membrane (either trapped in the glia or in the folds of the membrane, or even actually in the membrane structure) which cannot be easily removed by washing in sodium-free Ringer but which is affected by the calcium ion concentration.

We thank the Science Research Council for a grant towards the apparatus.

\section{S. G. Chamberlain \\ G. A. Kerkut}

Department of Physiology and Biochemistry,

University of Southampton.

Received July 7,1967 .

${ }^{1}$ Oomura, Y., Maeno, T., Ozaki, S., and Nakashima, Y., Seitai No Kagaku, 13, 83 (1962).

' Gerasimov, V. D., Kostyuk, P. G., and Aiskii, V. A., Bull. Exp. Biol. Med., 58, 3 (1964).

${ }^{3}$ Meves, H., Pflüg. Arch., 289, Hft. 2, S.R. 10 (1966).

4 Kerkut, (r. A., and Gardner, D. R., Comp. Biochem. Physiol., 20, 147 (1967).

s Hagiwara, S., and Naka, K., J. Gen. Physiol., 48, 141 (1964).

- Taylor, R. E., Moore, J. W., and Cole, K. S., Biophys. J., 1, 161 (1960).

' Hodgkin, A. X., and Huxley, A. F., J. Physiol., 116, 449 (1952).

\section{Amnesia induced by Scopolamine and its Temporal Variations}

AN anticholinesterase drug, diisopropylfluorophosphate (DFP), has been reported to produce weak amnesia for habits learned $30 \mathrm{~min}$ before its intracerebral injection, no amnesia for habits learned 3 days before and considerable amnesia for habits 5 and 14 days old ${ }^{1}$. There is also no amnesia for habits learned 1 day before injection of this drug (unpublished results of Deutsch and Stone). One of the effects of DFP is to slow down the destruction of the transmitter acetylcholine, thus permitting it to accumulate, and so DFP may block conduction at a synapse. This action would particularly affect a synapse where the amount of acetylcholine ejected during transmission is high, because accumulation sufficient to cause a block would in this case be quickly reached.

The temporal variations in amnesia induced by anti. cholinesterase have therefore been interpreted ${ }^{2,3}$ as showing that after the learning experience there is a gradual change in the level of transmitter ejected by a synapse during transmission. This level would be high immediately after learning (during temporary storage) and would drop rapidly to a low point, from which it would slowly increase to a new high level (underlying the long-term memory of a habit).

This hypothesis was tested in an experiment paralleling the one using DFP already reported ${ }^{1}$, but injecting the 